\title{
Pharmacokinetics of Tramadol and Celecoxib in Japanese and Caucasian Subjects Following Administration of Co-Crystal of Tramadol-Celecoxib (CTC): A Randomised, Open-Label Study
}

\author{
Helen Dooner ${ }^{1}$. Gill Mundin ${ }^{1} \cdot$ Sabine Mersmann ${ }^{2,3} \cdot$ Carla Bennett $^{1}{ }^{1} \cdot$ Ulrike Lorch $^{4}\left(\mathbb{C} \cdot\right.$ Mercedes Encabo $^{5}(1)$. \\ Marisol Escriche ${ }^{5}$. Gregorio Encina ${ }^{5}$ (D) Kevin Smith ${ }^{1}$
}

Published online: 28 June 2018

(c) The Author(s) 2018

\begin{abstract}
Background and Objectives Co-Crystal of Tramadol-Celecoxib (CTC) is a first-in-class active pharmaceutical ingredient (API-API) co-crystal of rac-tramadol. $\mathrm{HCl}$ and celecoxib in a 1:1 molecular ratio (100 mg CTC: $44 \mathrm{mg}$ rac-tramadol.HCl and $56 \mathrm{mg}$ celecoxib). Tramadol and celecoxib pharmacokinetics are modified after CTC administration versus administration of reference products. This randomised, open-label, crossover, phase 1 study assessed CTC pharmacokinetics, dose proportionality, safety and tolerability in Japanese and Caucasian subjects.

Methods CTC $(100,150$ and $200 \mathrm{mg})$ was administered orally to healthy Japanese/Caucasian subjects. Tramadol, $O$-desmethyltramadol and celecoxib plasma concentrations were determined pre-dose and up to $48 \mathrm{~h}$ post-dose. Maximum observed plasma concentration $\left(C_{\max }\right)$, and area under the plasma concentration-time curve from dosing to last measurable concentration $\left(\mathrm{AUC}_{t}\right)$ and from dosing extrapolated to infinity $\left(\mathrm{AUC}_{\infty}\right)$ were evaluated. Dose proportionality was assessed in a dose-adjusted bioavailability analysis of variance and in a power model. Inter-cohort comparability of pharmacokinetic exposure was confirmed if the ratio (Japanese cohort/Caucasian cohort) of geometric least-squares means and corresponding $90 \%$ confidence intervals were $80-125 \%$. Post hoc weight-adjusted comparability analyses were performed. Safety was assessed throughout.

Results Sixty subjects (21 males/9 females per cohort) were randomised; 57 completed the study. Cohorts were age and BMI matched; there were expected inter-cohort weight differences. Exposure to each analyte increased in both cohorts with increasing CTC dose. Tramadol's pharmacokinetic exposure was comparable between cohorts after adjusting for body weight; the pharmacokinetic exposure of $O$-desmethyltramadol and celecoxib was increased in Japanese subjects.

Conclusions Differences in pharmacokinetics were not sufficient to suggest that CTC dose adjustment is required in Japanese subjects.
\end{abstract}

Clinical Trial Registration EudraCT: 2015-003071-29.

Electronic supplementary material The online version of this article (https://doi.org/10.1007/s13318-018-0491-9) contains supplementary material, which is available to authorized users.

Helen Dooner

Helen.Dooner@mundipharma-rd.eu

1 Mundipharma Research Ltd, Cambridge Science Park, Milton Road, Cambridge CB4 OAB, UK

2 Mundipharma Research GmbH \& Co. KG, Höhenstraße 10, 65549 Limburg, Germany
3 Present Address: PRA Health Sciences, Gottlieb-Daimler-Straße 10, 68165 Mannheim, Germany

4 Richmond Pharmacology Ltd, St George's University London, Cranmer Terrace, Tooting, London SW17 0RE, UK

5 Laboratorios del Dr. Esteve, S.A.U., Parc Cientific Barcelona, C/Baldiri Reixac 4-8, 08028 Barcelona, Spain 


\section{Key Points}

Co-Crystal of Tramadol-Celecoxib (CTC) is a firstin-class active pharmaceutical ingredient (API-API) co-crystal of rac-tramadol. $\mathrm{HCl}$ and celecoxib in a 1:1 molecular ratio (100 $\mathrm{mg}$ CTC: $44 \mathrm{mg}$ rac-tramadol. $\mathrm{HCl}$ and $56 \mathrm{mg}$ celecoxib).

In this phase 1 study in Japanese and Caucasian subjects, the pharmacokinetic exposure of tramadol after CTC administration was comparable between the two cohorts (after adjusting for body weight). The pharmacokinetic exposure of $O$-desmethyltramadol and celecoxib was increased in Japanese subjects. CTC was well tolerated.

Differences in pharmacokinetics following CTC administration were not sufficient to suggest that dose adjustment is required in Japanese subjects.

\section{Introduction}

Co-crystallisation of an active pharmaceutical ingredient (API), with either a non-active coformer or another API, may provide improved physicochemical and pharmacokinetic characteristics, compared with commercially available single entity 'reference' products [1-3]. API-API co-crystals are novel drug formulations [1-3] and may be of particular value in the treatment of moderate to severe acute pain, where a multimodal approach to analgesia is recommended [4] and unmet needs, such as tolerability issues and limited efficacy, persist [4-6]. Co-Crystal of Tramadol-Celecoxib (CTC) is a first-in-class API-API co-crystal consisting of rac-tramadol.hydrochloride $(\mathrm{HCl})$ and celecoxib in a $1: 1$ molecular ratio (so that $100 \mathrm{mg}$ of CTC contains $44 \mathrm{mg}$ ractramadol.HCl and $56 \mathrm{mg}$ celecoxib). CTC combines four complementary mechanisms of action-cyclooxygenase-2 inhibition, $\mu$-opioid receptor agonism, noradrenaline reuptake inhibition and serotonin reuptake inhibition-thereby providing a potential means of delivering multimodal analgesia [7].

CTC is in development for the treatment of moderate to severe acute pain. In vitro analytical studies demonstrated that physicochemical properties, such as intrinsic dissolution rates, of both tramadol and celecoxib are modified by co-crystallisation-the intrinsic dissolution rate of celecoxib is faster from the co-crystal than from celecoxib alone, and that of tramadol slower than from tramadol. $\mathrm{HCl}$ alone [7]. In preclinical in vivo studies, synergistic antinociceptive effects occurred without any such synergism in measures of adverse effects [8]. CTC (100, 150 and $200 \mathrm{mg}$ ) was efficacious in a phase 2 clinical trial of moderate to severe acute dental pain [9]. The clinical pharmacokinetics of CTC were established in two key phase 1 trials, in which administration of single or multiple doses of $200 \mathrm{mg}$ CTC resulted in modified tramadol and celecoxib pharmacokinetic profiles, compared with administration of reference products alone or in free combination. For tramadol, a lower maximum observed plasma concentration $\left(C_{\max }\right)$ and slightly prolonged time to $C_{\max }$ $\left(T_{\max }\right)$ were observed with CTC. The $C_{\max }$ of celecoxib was lower than after administration of celecoxib alone and the $T_{\max }$ faster than after either celecoxib alone or in free combination with tramadol $[10,11]$.

The majority of subjects in these phase 1 and 2 clinical trials were white or Caucasian [9-11]. The pharmacokinetics and metabolism of standard-formulation tramadol and celecoxib are affected by genetic polymorphisms of cytochrome P450 (CYP) 2D6 and CYP2C9, respectively $[12,13]$. Certain polymorphisms are more common in some Asian populations, including in Japanese subjects [13-17]. Therefore, as part of the ongoing CTC clinical development programme, it was considered important to assess pharmacokinetics in Japanese subjects and to compare these with results obtained in Caucasian subjects. The primary objective of the current study was to assess the pharmacokinetics of three single doses of CTC (100, 150 and $200 \mathrm{mg}$ ) in both Japanese and Caucasian subjects. Secondary objectives were to assess the dose proportionality, safety and tolerability of these CTC doses.

\section{Methods}

\subsection{Subjects}

Subjects were male or female Japanese and Caucasian volunteers aged 20-45 years who were in good health according to medical history, physical examination, vital signs, electrocardiogram (ECG) and laboratory tests, and who had a body mass index (BMI) of $18.0-25.0 \mathrm{~kg} / \mathrm{m}^{2}$ and body weight of 50-90 kg. Japanese and Caucasian cohorts were sex- and BMI matched, as closely as possible. Subjects were defined as Japanese if they were born in Japan, had two parents of Japanese descent and had not resided outside Japan for $>5$ years. Key exclusion criteria included pregnancy and lactation; a history of significant gastrointestinal, liver or kidney disease, or other conditions that might affect drug pharmacokinetics; use of opioids or opioid antagonists within 30 days of enrolment; and use of any medication within 7 days of, or during, the study. Full inclusion and exclusion criteria are included in Online Resource 1. 


\subsection{Study Design}

This phase 1 study (EudraCT No 2015-003071-29) was conducted between 20 October 2015 and 17 December 2015 . The trial was a randomised, open-label, two-cohort, threeperiod, crossover, single-dose bioavailability study, conducted in a single centre in the UK by a contract research organisation (Richmond Pharmacology Ltd). Screening and subject eligibility assessments took place between days -21 and -1 , and enrolment and randomisation took place between day -1 and day 1 . Subjects were randomised, via an automated system and central randomisation list, to receive each of three oral doses of CTC once over the course of three dosing periods, according to six pre-determined treatment sequences (Fig. 1). The treatments were $100 \mathrm{mg}$ CTC $(1 \times 100 \mathrm{mg}$ tablet consisting of $44 \mathrm{mg}$ ractramadol. $\mathrm{HCl}$ and $56 \mathrm{mg}$ celecoxib; Laboratorios del Dr. Esteve, S.A.U.), $150 \mathrm{mg}$ CTC $(1 \times 150 \mathrm{mg}$ tablet consisting of $66 \mathrm{mg}$ rac-tramadol. $\mathrm{HCl}$ and $84 \mathrm{mg}$ celecoxib) and $200 \mathrm{mg}$ CTC $(2 \times 100 \mathrm{mg}$ tablets, total dose consisting of $88 \mathrm{mg}$ rac-tramadol. $\mathrm{HCl}$ and $112 \mathrm{mg}$ celecoxib). Each dose was separated by a washout period of at least 10 days. For each dosing period, subjects entered the study clinic on day -1 and remained until pharmacokinetic and safety assessments were completed at $48 \mathrm{~h}$ post-dose on day 3 . Dosing occurred on day 1 of each period, under fasting conditions (subjects fasted from $10 \mathrm{~h}$ pre-dose until at least $4 \mathrm{~h}$ postdose). Subjects received standardised meals and fluid intake during the remainder of each in-patient stay. During each inpatient stay and for $48 \mathrm{~h}$ before check-in to each study period subjects had to refrain from the consumption of grapefruit juice and any food or drinks containing alcohol, caffeine, poppy seeds or xanthine. Tobacco use was not permitted during the study or for 90 days before the first administration of CTC. A follow-up visit was conducted 7-10 days after final CTC administration. The maximum study length was 52 days per subject.

The study drug was manufactured and packaged according to Good Manufacturing Practice and supplied to the principal investigator in labelled containers by the manufacturer (Laboratorios del Dr. Esteve, S.A.U.).

The study protocol was approved by an ethics committee (South Central-Berkshire B Research Ethics Committee, UK; IRAS:188440; REC reference: 15/SC/0549). The study sponsor was Mundipharma Research Ltd. The study was performed in accordance with Good Clinical Practice guidelines, according to the principles of the Declaration of Helsinki and the International Conference on Harmonization Good Clinical Practice guidelines. All participants provided written informed consent.

\subsection{Blood Sampling}

Blood samples were taken for pharmacokinetic analysis predose and at $0.5,0.75,1,1.25,1.5,1.75,2,2.5,3,3.5,4,5$, $6,8,10,12,16,24,36$ and $48 \mathrm{~h}$ after dosing in each of the three dosing periods. Methods for blood sample collection have been described in detail elsewhere [10]. In brief, blood samples were collected in $\mathrm{K}_{2}$-EDTA-containing tubes and centrifuged for $15 \mathrm{~min}$ at $1500 \mathrm{~g}$ and $4{ }^{\circ} \mathrm{C}$, within $30 \mathrm{~min}$ of collection. Following centrifugation, plasma was separated and stored at $-80^{\circ} \mathrm{C}$.

\subsection{Bioanalytical Assay}

Plasma concentrations of tramadol, $O$-desmethyltramadol (M1; tramadol's primary metabolite) and celecoxib were measured using validated high-performance liquid chromatography with tandem mass spectrometry. Samples $(0.05 \mathrm{~mL})$ were extracted by solid-phase extraction and
Fig. 1 Subject disposition. $A E$ adverse event, $C T C$ CoCrystal of Tramadol-Celecoxib. $* A=100 \mathrm{mg}$ CTC, $B=150 \mathrm{mg}$ CTC, $C=200 \mathrm{mg}$ CTC

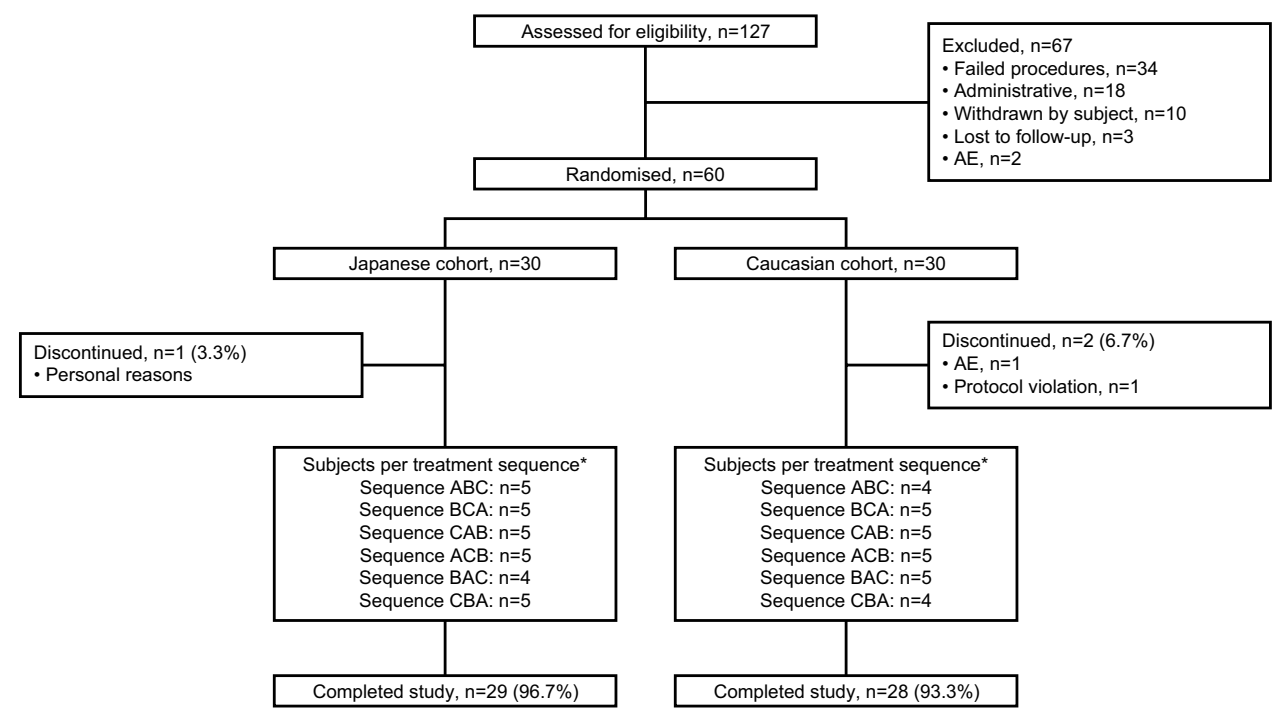


separated by reverse-phase liquid chromatography on a XBridge C18 column $(3.5 \mu \mathrm{m} 50 \times 2.1 \mathrm{~mm}$, Waters Corporation, Milford, MA, USA), using a gradient of water with $0.1 \%$ formic acid, and acetonitrile with $0.1 \%$ formic acid as a mobile phase. Detection was performed via tandem mass spectrometry on an API 4000 triple quadrupole mass spectrometer (Sciex, Ontario, Canada) using Turbo Ion spray ionisation. Propranolol and E-6087, a cyclooxygenase-2 inhibitor, were used as internal standards. Linearity and range; selectivity; specificity in the presence of concomitant medication; intra- and inter-run precision and accuracy; limits of quantification; dilution integrity; carry-over; recovery; matrix effect; and stability in an autosampler at room temperature, after freeze-thaw cycles and long-term, were evaluated during method validation. The lower and upper limits of quantification were 4.00 and $640.00,1.00$ and 160.00 , and 2.50 and $1000.00 \mathrm{ng} / \mathrm{mL}$, for tramadol, M1 and celecoxib, respectively. Samples below these limits were not quantified and were considered to be below the lower limit of quantification. Samples above the limit of quantification were reassayed after dilution, using a dilution factor equal to or lower than the maximum dilution factor tested during method validation (dilution factor of 10). The inter-run accuracy (nominal values) varied from 99.81 to $103.65 \%$ for tramadol, 96.21 to $103.69 \%$ for M1, and 105.84 to $108.68 \%$ for celecoxib, and $94.2,92.7$ and $109.5 \%$ for limits of quantification, respectively. The inter-run precision (coefficient of variation) varied from 4.77 to $8.67 \%$ for tramadol, 7.67 to $9.38 \%$ for M1 and 6.19 to $7.05 \%$ for celecoxib, and 15.5 , 15.3 and $10.1 \%$ for limits of quantification, respectively. Assay specificity was assessed using six independent matrix sources from Caucasian and Japanese volunteers, verified for the absence of interference and compared with the respective limits of quantification at the retention times and mass transitions of analytes and internal standards. Absolute recovery was 97.9-99.2, 96.5-101.0 and 74.1-78.0\% for tramadol, M1 and celecoxib, respectively. The stability of the samples at the bench was $25 \mathrm{~h}$ and samples were stable under three freeze-thaw cycles. The maximum sample storage duration was 76 days; long-term stability of frozen samples was 160 days.

\subsection{Pharmacokinetic Parameters}

The primary pharmacokinetic parameters were tramadol and celecoxib $C_{\max }$ and area under the plasma concentration-time curve measured from the time of dosing to the last measurable concentration $\left(\mathrm{AUC}_{t}\right)$. Other pharmacokinetic parameters included area under the plasma concentration-time curve measured from the time of dosing and extrapolated to infinity $\left(\mathrm{AUC}_{\infty}\right)$; time to $C_{\max }\left(T_{\max }\right)$; and terminal phase half-life $\left(T_{1 / 2 Z}\right)$.

\subsection{Safety}

Safety was evaluated via the assessment of adverse events (AEs), standard laboratory evaluations, physical examination, vital signs (including pulse oximetry) and 12-lead ECG. AEs were monitored throughout the study and severity was graded by the investigator. All other safety assessments were conducted during initial screening and at the end-ofstudy follow-up visit. In each dosing period, vital signs were also assessed pre-dose and at 1, 2, 4, 6, 8, 12, 16, 24, 36 and $48 \mathrm{~h}$ post-dose; physical examination was conducted pre-dose and at $48 \mathrm{~h}$ post-dose; and ECG at $2 \mathrm{~h}$ post-dose.

\subsection{Data Analyses}

The primary objective was not associated with any formal statistical hypotheses and therefore sample size was calculated based on the number of subjects required to assess the dose proportionality of CTC in each cohort (a secondary study objective). Using a dose-adjusted bioavailability analysis of variance (ANOVA) model, dose proportionality of two CTC doses would be demonstrated if the $90 \%$ confidence intervals (CI) for the geometric least-squares means of $\mathrm{AUC}_{t}$ and $C_{\text {max }}$ fell entirely between 80.00 and $125.00 \%$. The sample size calculation was performed using nQuery (Cork, Ireland) applying the $t$ test of equivalence in ratio of means for crossover designs, assuming true ratios of $100 \%$ between CTC doses and a standard deviation of the period differences on the log scale of 0.330 . No adjustment was made for multiple testing. Twenty-six subjects were calculated to be required per cohort to provide $90 \%$ power to determine dose proportionality. With an assumption that approximately $10 \%$ of randomised subjects would not be eligible for inclusion in the pharmacokinetic population or would not provide sufficient valid pharmacokinetic parameters to be included in the statistical analysis for a comparison, 30 subjects were randomised within each cohort.

The intention-to-treat (ITT) population consisted of all randomised subjects. The pharmacokinetic population consisted of all subjects who received one dose of CTC and from whom at least one valid pharmacokinetic parameter was recorded. The safety population consisted of all subjects who received at least one dose of CTC.

Pharmacokinetic parameters were summarised descriptively by CTC dose in each cohort. $\mathrm{AUC}_{\infty}$ was calculated from the ratio of the final observed plasma concentration to the terminal phase rate constant; this was added to $\mathrm{AUC}_{t}$. $\left(\mathrm{AUC}_{t}\right.$ was calculated using the linear up/log down trapezoidal method). Pharmacokinetic calculations were conducted using Phoenix WinNonlin, Version 6.4.

Within-cohort dose proportionality for tramadol and celecoxib was calculated by evaluating $\mathrm{AUC}_{t}, \mathrm{AUC}_{\infty}$ and $C_{\max }$ using two methods; the dose-adjusted bioavailability 
ANOVA model and a power model. In the ANOVA, proportionality of two CTC doses was demonstrated if $90 \%$ CI values for the ratio of geometric least-squares means for $\mathrm{AUC}_{t}$, $\mathrm{AUC}_{\infty}$ and $C_{\max }$ fell between 80.00 and $125.00 \%$. Dose proportionality was calculated using $100 \mathrm{mg}$ CTC as a reference dose (i.e. $150 \mathrm{mg}$ CTC and $200 \mathrm{mg}$ CTC were each compared to $100 \mathrm{mg} \mathrm{CTC}$ ). In the power model, dose proportionality was demonstrated if the $90 \%$ CIs of the slope estimates fell entirely between the critical region (0.6781-1.3219). The key modelling assumption in the power model was that the logarithm of each pharmacokinetic variable was linearly related to the logarithm of the dose.

For comparisons of pharmacokinetic exposure across cohorts, $C_{\max }, \mathrm{AUC}_{t}$ and $\mathrm{AUC}_{\infty}$ were analysed on a log scale using an ANOVA model with fixed effects for sequence, period and cohort. Test/reference (Japanese cohort/Caucasian cohort) ratios were calculated by transforming the difference between the natural log least-squares means back to the original scale and multiplying by 100 . Comparability of tramadol, M1 or celecoxib pharmacokinetic exposure between cohorts was to be assumed if the $90 \%$ CIs for a test/reference ratio were $>80$ and $<125 \%$. A post hoc weight-adjusted inter-cohort comparability analysis was also performed. Statistical programming and analyses were performed using SAS ${ }^{\circledR}$ version 9.3 or higher (SAS Institute, Cary, USA).

\section{Results}

\subsection{Subjects}

One hundred and twenty-seven subjects were assessed for study eligibility; of these, 67 failed screening and 60 participated in the study. All 60 study subjects were randomised and included in the ITT, pharmacokinetic and safety analysis populations (30 in each cohort). Overall, 57 subjects completed the study [29 (96.7\%) subjects in the Japanese cohort and 28 (93.3\%) subjects in the Caucasian cohort; Fig. 1]. One subject from the Japanese cohort withdrew consent (and left the study and returned to Japan) prior to administration of $200 \mathrm{mg}$ CTC in the third dosing period. Two Caucasian subjects discontinued prematurely, one due to a protocol violation [a positive test for cannabis at the second dosing period check-in (subject did not receive 100 or $150 \mathrm{mg}$ CTC)] and one due to a non-serious tooth infection (subject did not receive $200 \mathrm{mg}$ CTC in the third dosing period). Another Caucasian subject experienced regurgitation during the third dosing period (during which the subject had received $200 \mathrm{mg}$ CTC), which invalidated the pharmacokinetic data obtained in this period. Subjects without valid data for a specific dosing period were excluded from the pharmacokinetic analyses for that dose. In the case of safety analyses, subjects were included for those doses that they received.

The mean age of subjects in the Japanese and Caucasian cohorts was 31.5 and 30.0 years, respectively. Both cohorts included 21 males and 9 females. Although cohorts were BMI matched - with mean BMI values of 21.6 and 22.1 in the Japanese and Caucasian cohorts, respectively_Japanese subjects were, on average, shorter and lighter than Caucasian subjects (Table 1).

\subsection{Pharmacokinetics}

\subsubsection{Tramadol}

Tramadol plasma concentration-time curves obtained after administration of CTC to Japanese and Caucasian subjects are shown in Fig. 2a and b, respectively. In both cohorts, tramadol $C_{\max }, \mathrm{AUC}_{t}$ and $\mathrm{AUC}_{\infty}$ exhibited dose proportionality, as assessed by dose-adjusted bioavailability analysis and power model analysis (Tables 2 and 3, respectively).

$T_{\max }$ values were between 2.75 and $3.50 \mathrm{~h}$ (Table 4). Comparability of primary pharmacokinetic parameters between the Japanese and Caucasian cohorts could not be formally demonstrated for tramadol as the upper $90 \% \mathrm{CI}$ values for test/reference ratios exceeded 125\% (Table 5). However, when repeating the analysis adjusting for subjects' weight, $C_{\max }$ for tramadol was comparable in the two cohorts for all three doses (estimated ratios of 105.56, 109.25 and $108.73 \%$ for 100,150 and $200 \mathrm{mg}$ CTC, respectively, with 90\% CIs between 80 and 125\%; Table 5). While weightadjusted AUC ratios fell between 80 and $125 \%$, most upper $90 \%$ CI values exceeded $125 \%$ (Table 5).

\subsubsection{M1}

Mean M1 plasma concentration-time curves in Japanese and Caucasian subjects are shown in Fig. 3a and b. In both

Table 1 Subject demographics

\begin{tabular}{lcc}
\hline Characteristic & $\begin{array}{l}\text { Japanese cohort } \\
n=30\end{array}$ & $\begin{array}{l}\text { Caucasian cohort } \\
n=30\end{array}$ \\
\hline Age, years; mean (SD) & $31.5(6.05)$ & $30.0(6.65)$ \\
Gender; $n$ (\%) & & \\
Male & $21(70.0)$ & $21(70.0)$ \\
Female & $9(30.0)$ & $9(30.0)$ \\
Weight, kg; mean (SD) & $60.9(7.9)$ & $67.4(8.8)$ \\
Height, cm; mean (SD) & $167.7(8.5)$ & $174.5(8.6)$ \\
Body mass index, kg/m²; & $21.6(1.6)$ & $22.1(1.6)$ \\
$\quad$ mean (SD) & & \\
\hline
\end{tabular}

$S D$ standard deviation 
Fig. 2 Mean plasma concentration-time curves for tramadol in Japanese (a) and Caucasian (b) cohorts. CTC Co-Crystal of Tramadol-Celecoxib
Table 2 Dose proportionality of tramadol and celecoxib pharmacokinetic parameters after CTC administration in Japanese and Caucasian subjects (dose-adjusted bioavailability analysis)
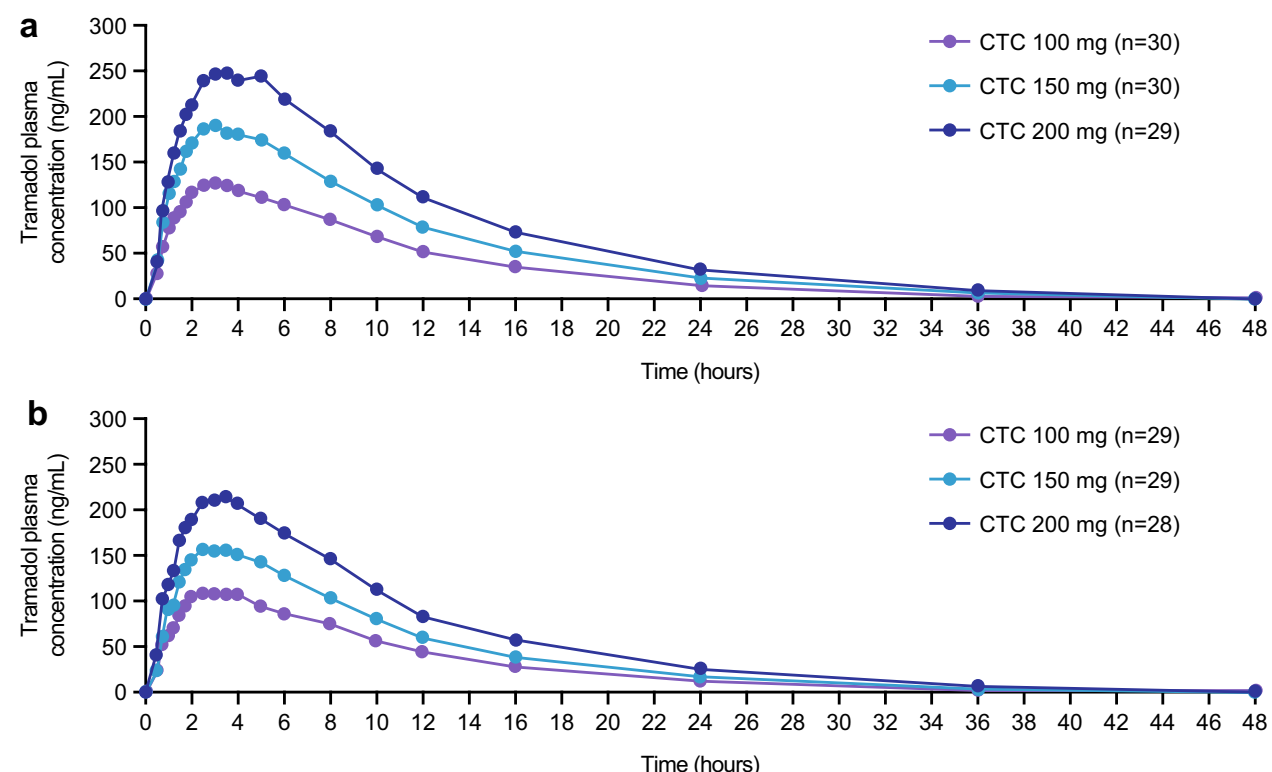

\begin{tabular}{|c|c|c|c|c|c|c|}
\hline \multirow[t]{2}{*}{ Parameter } & \multirow{2}{*}{$\begin{array}{l}\text { Test CTC } \\
\text { dose }^{\mathrm{a}}(\mathrm{mg})\end{array}$} & \multirow[t]{2}{*}{ Number of subjects } & \multicolumn{2}{|c|}{ Japanese cohort } & \multicolumn{2}{|c|}{ Caucasian cohort } \\
\hline & & & $\begin{array}{l}\text { Ratio (test/ } \\
\text { reference }{ }^{\mathrm{a}} \text {; } \\
\%)\end{array}$ & $90 \% \mathrm{CI}$ & $\begin{array}{l}\text { Ratio (test/ } \\
\text { reference }{ }^{a} \text {; } \\
\%)\end{array}$ & $90 \% \mathrm{CI}$ \\
\hline \multicolumn{7}{|l|}{ Tramadol } \\
\hline \multirow[t]{2}{*}{$C_{\max }$} & 150 & $n=30^{\mathrm{b}} ; n=29^{\mathrm{c}}$ & 98.64 & $92.87,104.76$ & 95.90 & $92.34,99.60$ \\
\hline & 200 & $n=29^{\mathrm{b}} ; n=27^{\mathrm{c}}$ & 97.68 & $91.84,103.90$ & 96.32 & $92.57,100.22$ \\
\hline \multirow[t]{2}{*}{$\mathrm{AUC}_{t}$} & 150 & $n=30^{\mathrm{b}} ; n=29^{\mathrm{c}}$ & 104.51 & $98.66,110.71$ & 95.52 & $91.60,99.61$ \\
\hline & 200 & $n=29^{\mathrm{b}} ; n=27^{\mathrm{c}}$ & 106.97 & $100.83,113.48$ & 99.67 & $95.47,104.05$ \\
\hline \multirow[t]{2}{*}{$\mathrm{AUC}_{\infty}$} & 150 & $n=30^{\mathrm{b}} ; n=29^{\mathrm{c}}$ & 102.74 & $97.05,108.76$ & 94.43 & $90.57,98.45$ \\
\hline & 200 & $n=29^{\mathrm{b}} ; n=27^{\mathrm{c}}$ & 104.47 & $98.54,110.77$ & 98.11 & $93.95,102.45$ \\
\hline \multicolumn{7}{|l|}{ Celecoxib } \\
\hline \multirow[t]{2}{*}{$C_{\max }$} & 150 & $n=30^{\mathrm{b}} ; n=29^{\mathrm{c}}$ & 88.26 & $80.25,97.08$ & 84.55 & $75.84,94.25$ \\
\hline & 200 & $n=29^{\mathrm{b}} ; n=27^{\mathrm{c}}$ & 82.61 & $74.98,91.03$ & 84.06 & $75.00,94.20$ \\
\hline \multirow[t]{2}{*}{$\mathrm{AUC}_{t}$} & 150 & $n=30^{\mathrm{b}} ; n=29^{\mathrm{c}}$ & 97.14 & $92.35,102.18$ & 92.86 & $88.67,97.24$ \\
\hline & 200 & $n=29^{\mathrm{b}} ; n=27^{\mathrm{c}}$ & 100.39 & $95.32,105.73$ & 93.07 & $88.91,97.42$ \\
\hline \multirow[t]{2}{*}{$\mathrm{AUC}_{\infty}$} & 150 & $n=27^{\mathrm{b}} ; n=23^{\mathrm{c}}$ & 97.56 & $92.63,102.77$ & 93.30 & $88.13,98.76$ \\
\hline & 200 & $n=27^{\mathrm{b}} ; n=23^{\mathrm{c}}$ & 100.39 & $95.08,106.00$ & 95.02 & $90.00,100.31$ \\
\hline
\end{tabular}

$A U C_{\infty}$ area under the plasma concentration-time curve measured from the time of dosing and extrapolated to infinity, $A U C_{t}$ area under the plasma concentration-time curve measured from the time of dosing to the last measurable concentration, $C I$ confidence interval, $C_{\max }$ maximum observed plasma concentration, $C T C$ Co-Crystal of Tramadol-Celecoxib

${ }^{\text {a }}$ Reference dose $=100 \mathrm{mg}$ CTC

${ }^{\mathrm{b} J a p a n e s e}$ cohort

${ }^{\mathrm{c}}$ Caucasian cohort cohorts, $C_{\max }, \mathrm{AUC}_{t}$ and $\mathrm{AUC}_{\infty}$ increased with increasing dose (Table 6).

$T_{\max }$ was between 3.50 and $4.00 \mathrm{~h}$ (Table 6). In intercohort assessments, the majority of test/reference ratios and all upper $90 \%$ CI values for 100, 150 and $200 \mathrm{mg} \mathrm{CTC}$ were outside the pre-determined comparability range, including after adjustment for body weight (Table 7).

M1/tramadol ratios were similar between cohorts and across CTC doses. For mean $\mathrm{AUC}_{t}$, M1/tramadol ratios ranged from $0.1848(200 \mathrm{mg}$ CTC) to $0.2084(100 \mathrm{mg})$ in 
Table 3 Dose proportionality of tramadol and celecoxib pharmacokinetic parameters after CTC administration in Japanese and Caucasian subjects (power model analysis)

\begin{tabular}{llllll}
\hline Parameter & \multicolumn{2}{l}{ Japanese cohort $\left(n=89^{\mathrm{a}}\right)$} & & \multicolumn{2}{l}{$\begin{array}{l}\text { Caucasian cohort } \\
\left(n=87^{\mathrm{a}}\right)\end{array}$} \\
& Slope & $90 \% \mathrm{CI}$ & & Slope & $90 \% \mathrm{CI}$ \\
\hline Tramadol & & & & \\
$C_{\max }$ & 0.97 & $0.88,1.05$ & & 0.94 & $0.88,1.00$ \\
$\mathrm{AUC}_{t}$ & 1.10 & $1.02,1.18$ & & 0.99 & $0.93,1.05$ \\
$\mathrm{AUC}_{\infty}$ & 1.06 & $0.98,1.15$ & & 0.96 & $0.90,1.03$ \\
Celecoxib & & & & \\
$C_{\text {max }}$ & 0.94 & $0.87,1.02$ & & 0.73 & $0.57,0.89$ \\
$\mathrm{AUC}_{t}$ & 1.02 & $0.94,1.09$ & & 0.89 & $0.82,0.96$ \\
$\mathrm{AUC}_{\infty}$ & 0.93 & $0.86,1.00$ & & 0.90 & $0.82,0.99$ \\
\hline
\end{tabular}

$A U C_{\infty}$ area under the plasma concentration-time curve measured from the time of dosing and extrapolated to infinity, $A U C_{t}$ area under the plasma concentration-time curve measured from the time of dosing to the last measurable concentration, $C I$ confidence interval, $C_{\max }$ maximum observed plasma concentration, CTC Co-Crystal of Tramadol-Celecoxib

${ }^{a} n=$ total number of data points from each cohort (i.e. after administration of 100,150 or $200 \mathrm{mg}$ CTC)

the Japanese cohort and 0.1996 (200 mg CTC) to 0.2129 $(150 \mathrm{mg})$ in the Caucasian cohort. For mean $\mathrm{AUC}_{\infty}$, $\mathrm{M} 1 /$ tramadol ratios ranged from 0.1902 (200 $\mathrm{mg} \mathrm{CTC}$ ) to $0.2171(100 \mathrm{mg})$ in the Japanese cohort and 0.2123 (200 mg CTC) to $0.2263(150 \mathrm{mg})$ in the Caucasian cohort. One Caucasian subject consistently demonstrated high tramadol levels and low M1 levels, resulting in low M1/tramadol ratios (0.0146-0.0223).

\subsubsection{Celecoxib}

Mean celecoxib plasma concentration-time curves are shown in Fig. 4a and b. Celecoxib $C_{\max }, \mathrm{AUC}_{t}$ and $\mathrm{AUC}_{\infty}$ exhibited dose proportionality in both cohorts (Table 2 and Table 3), with the exception of $C_{\max }$ in the Caucasian cohort, for which dose proportionality could not be demonstrated in the power model analysis (Table 3).

$T_{\max }$ values were between 1.75 and $3.00 \mathrm{~h}$ (Table 8). Intercohort comparability was demonstrated for AUC parameters at a dose of $100 \mathrm{mg} \mathrm{CTC}$ and similar results were seen for $\mathrm{AUC}_{\infty}$ at $150 \mathrm{mg}$. $\mathrm{AUC}_{t}$ was increased in the Japanese cohort (upper $90 \%$ CI values exceeded $125 \%$ ) after 150 and $200 \mathrm{mg}$ CTC (Table 9). Inter-cohort differences were similar for $C_{\max }$ and $\mathrm{AUC}_{\mathrm{t}}$ after body weight adjustment. In the case of $\mathrm{AUC}_{\infty}$, inter-cohort differences were absent across all three doses after body weight adjustment (Table 9).

\subsection{Safety}

No severe AEs, serious AEs or deaths were reported and there were no clinically significant changes in laboratory parameters, vital signs or ECGs. The proportion of subjects experiencing at least one $\mathrm{AE}$ after administration of each CTC dose is shown in Table 10. Overall, a total of 19 AEs occurred in 10 (33.3\%) Japanese subjects and 34 AEs occurred in 17 (56.7\%) Caucasian subjects. Eleven AEs in $5(16.7 \%)$ Japanese subjects were considered treatmentrelated, as were 19 AEs in 10 (33.3\%) Caucasian subjects. Most AEs were mild and occurred only once per cohort or treatment group. Of those occurring in more than $5 \%$ of subjects after any treatment, nausea was reported in $2(6.7 \%)$ Japanese and 5 (16.7\%) Caucasian subjects, dizziness in 3 (10.0\%) Japanese and 2 (6.7\%) Caucasian subjects, fatigue

Table 4 Summary of tramadol pharmacokinetic parameters after CTC administration in Japanese and Caucasian subjects

\begin{tabular}{|c|c|c|c|c|c|c|}
\hline \multirow[t]{2}{*}{ Parameter } & \multicolumn{3}{|l|}{ Japanese cohort } & \multicolumn{3}{|l|}{ Caucasian cohort } \\
\hline & $100 \mathrm{mg} \mathrm{CTC}(n=30)$ & $150 \mathrm{mg} \mathrm{CTC}(n=30)$ & $200 \mathrm{mg}$ CTC $(n=29)$ & $100 \mathrm{mg} \mathrm{CTC}(n=29)$ & $150 \mathrm{mg} \mathrm{CTC}(n=29)$ & $200 \mathrm{mg} \mathrm{CTC}(n=28)$ \\
\hline $\begin{array}{l}C_{\max }, \mathrm{ng} / \mathrm{mL} ; \text { mean } \\
\quad(\mathrm{CV})\end{array}$ & $137.5(26.5)$ & $203.5(22.0)$ & $269.7(23.7)$ & $118.4(23.1)$ & $170.4(26.3)$ & $226.0(22.9)$ \\
\hline $\begin{array}{l}\mathrm{AUC}_{t}, \mathrm{ng} \cdot \mathrm{h} / \mathrm{mL} \\
\text { mean }(\mathrm{CV})\end{array}$ & 1399.85 (45.4) & $2194.53(41.2)$ & 3022.75 (36.9) & $1192.71(36.7)$ & $1707.98(36.5)$ & 2385.78 (36.9) \\
\hline $\begin{array}{l}\mathrm{AUC}_{\infty}, \mathrm{ng} \cdot \mathrm{h} / \mathrm{mL} \\
\text { mean }(\mathrm{CV})\end{array}$ & $1477.83(43.8)$ & $2277.40(40.1)$ & $3117.55(36.6)$ & $1263.42(37.4)$ & $1788.89(37.1)$ & $2484.00(37.3)$ \\
\hline $\begin{array}{l}T_{\max }, \mathrm{h} ; \text { median } \\
\quad \text { (range) }\end{array}$ & $2.75(1.00-6.00)$ & $2.75(0.75-5.00)$ & $3.50(1.50-5.00)$ & $3.00(0.75-4.00)$ & $3.00(1.00-5.00)$ & $3.03(0.75-5.00)$ \\
\hline$T_{1 / 2 \mathrm{Z}}, \mathrm{h} ;$ mean $(\mathrm{SD})$ & $6.54(1.37)$ & $6.58(1.56)$ & $6.80(1.36)$ & $6.45(2.31)$ & $6.37(2.14)$ & $6.47(1.88)$ \\
\hline
\end{tabular}

$A U C_{\infty}$ area under the plasma concentration-time curve measured from the time of dosing and extrapolated to infinity, $A U C_{t}$ area under the plasma concentration-time curve measured from the time of dosing to the last measurable concentration, $C_{\max }$ maximum observed plasma concentration, CTC Co-Crystal of Tramadol-Celecoxib, $C V$ coefficient of variation (\%), SD standard deviation, $T_{\text {max }}$ time to reach maximum observed plasma concentration, $T_{1 / 2 Z}$ terminal phase half-life 
Table 5 Comparative bioavailability of tramadol after CTC administration in Japanese versus Caucasian subjects

\begin{tabular}{|c|c|c|c|c|c|c|}
\hline \multirow[t]{2}{*}{ Parameter } & \multirow[t]{2}{*}{ CTC dose (mg) } & \multirow[t]{2}{*}{ Number of subjects } & \multicolumn{2}{|l|}{ Non-weight adjusted } & \multicolumn{2}{|l|}{ Weight adjusted } \\
\hline & & & $\begin{array}{l}\text { Ratio (Japanese cohort/ } \\
\text { Caucasian cohort; \%) }\end{array}$ & $90 \% \mathrm{CI}$ & $\begin{array}{l}\text { Ratio (Japanese cohort/ } \\
\text { Caucasian cohort; \%) }\end{array}$ & $90 \% \mathrm{CI}$ \\
\hline \multirow[t]{3}{*}{$C_{\max }$} & 100 & $n=30^{\mathrm{a}} ; n=29^{\mathrm{b}}$ & 116.43 & $104.31,129.95$ & 105.56 & $95.22,117.02$ \\
\hline & 150 & $n=30^{\mathrm{a}} ; n=29^{\mathrm{b}}$ & 119.64 & $107.77,132.81$ & 109.25 & $98.97,120.59$ \\
\hline & 200 & $n=29^{\mathrm{a}} ; n=28^{\mathrm{b}}$ & 119.39 & $107.92,132.06$ & 108.73 & $98.92,119.50$ \\
\hline \multirow[t]{3}{*}{$\mathrm{AUC}_{t}$} & 100 & $n=30^{\mathrm{a}} ; n=29^{\mathrm{b}}$ & 117.75 & $98.65,140.54$ & 104.64 & $87.55,125.06$ \\
\hline & 150 & $n=30^{\mathrm{a}} ; n=29^{\mathrm{b}}$ & 128.81 & $108.82,152.46$ & 115.71 & $97.50,137.32$ \\
\hline & 200 & $n=29^{\mathrm{a}} ; n=28^{\mathrm{b}}$ & 126.88 & $107.88,149.24$ & 111.34 & $95.01,130.48$ \\
\hline \multirow[t]{3}{*}{$\mathrm{AUC}_{\infty}$} & 100 & $n=30^{\mathrm{a}} ; n=29^{\mathrm{b}}$ & 117.37 & $98.49,139.87$ & 104.64 & $87.64,124.94$ \\
\hline & 150 & $n=30^{\mathrm{a}} ; n=29^{\mathrm{b}}$ & 127.64 & $107.96,150.91$ & 114.91 & $96.91,136.26$ \\
\hline & 200 & $n=29^{\mathrm{a}} ; n=28^{\mathrm{b}}$ & 125.65 & $106.78,147.86$ & 110.38 & $94.10,129.48$ \\
\hline
\end{tabular}

$A U C_{\infty}$ area under the plasma concentration-time curve measured from the time of dosing and extrapolated to infinity, $A U C_{t}$ area under the plasma concentration-time curve measured from the time of dosing to the last measurable concentration, $C_{\text {max }}$ maximum observed plasma concentration, CTC Co-Crystal of Tramadol-Celecoxib, CI confidence interval

a Japanese cohort

${ }^{\mathrm{b}}$ Caucasian cohort

Fig. 3 Mean plasma concentration-time curves for $O$-desmethyltramadol (M1) in Japanese (a) and Caucasian (b) cohorts. CTC Co-Crystal of TramadolCelecoxib

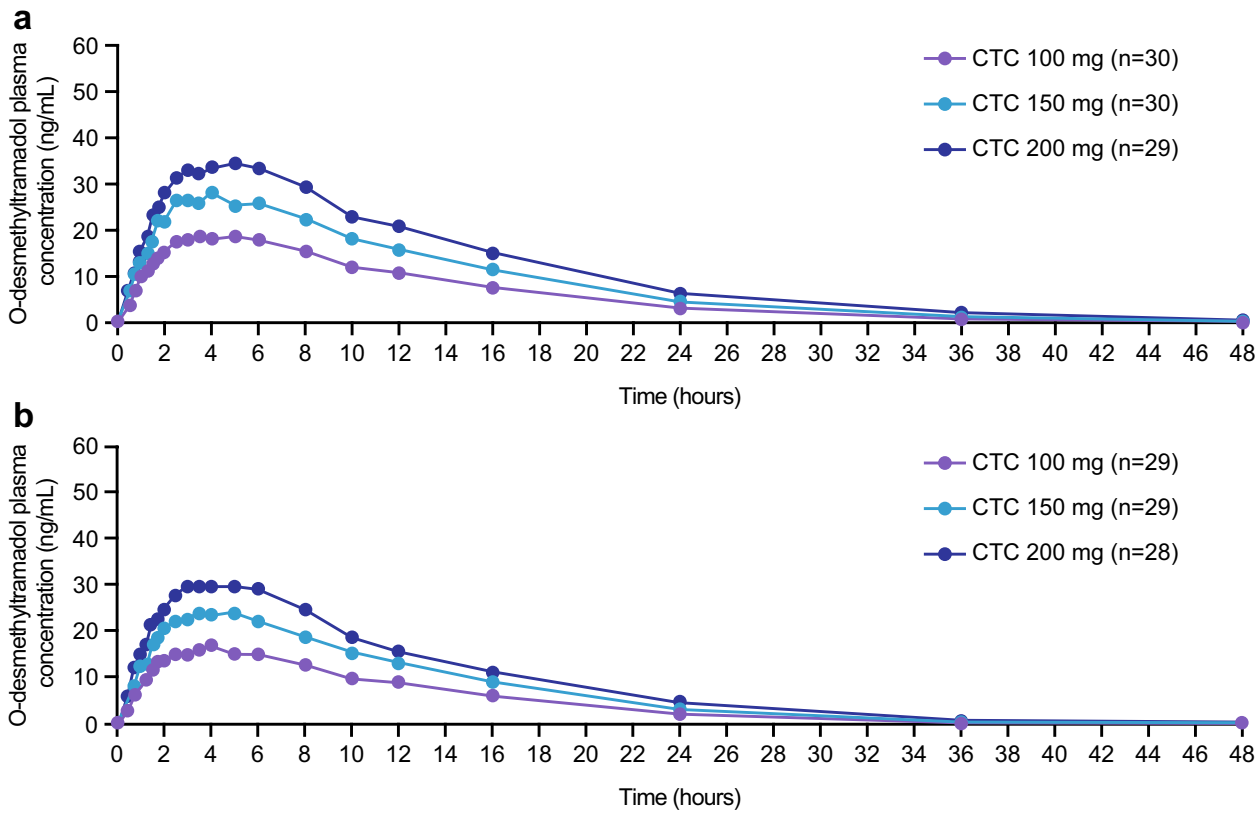

in $2(6.7 \%)$ Japanese subjects and hyperhidrosis in $2(6.7 \%)$ Caucasian subjects (Table 10).

\section{Discussion}

In the current study, exposure to tramadol, M1 and celecoxib increased with the administration of increasing doses of CTC in both Japanese and Caucasian cohorts. The pharmacokinetic exposure of tramadol was comparable between these two cohorts after adjusting for body weight, while that of M1 and celecoxib was increased in Japanese subjects. M1/tramadol ratios were similar between cohorts and across CTC doses. CTC was well tolerated at all doses in both cohorts. Although the highest number of AEs occurred after administration of $200 \mathrm{mg}$ CTC in both cohorts, the difference between dose groups was rather small overall and thus may not indicate that AEs were dose related. In summary, the study's findings suggest that, relative to doses provided to Caucasian subjects, no dose adjustment is required before CTC is administered to Japanese subjects. 
Table 6 Summary of O-desmethyltramadol (M1) pharmacokinetic parameters after CTC administration in Japanese and Caucasian subjects

\begin{tabular}{|c|c|c|c|c|c|c|}
\hline \multirow[t]{2}{*}{ Parameter } & \multicolumn{3}{|l|}{ Japanese cohort } & \multicolumn{3}{|l|}{ Caucasian cohort } \\
\hline & $100 \mathrm{mg}$ CTC $(n=30)$ & $150 \mathrm{mg} \mathrm{CTC}(n=30)$ & $200 \mathrm{mg}$ CTC $(n=29)$ & $100 \mathrm{mg} \mathrm{CTC}(n=29)$ & $150 \mathrm{mg}$ CTC $(n=29)$ & $200 \mathrm{mg}$ CTC $(n=28)$ \\
\hline $\begin{array}{r}C_{\max }, \mathrm{ng} / \mathrm{mL} ; \\
\text { mean }(\mathrm{CV})\end{array}$ & $19.93(49.8)$ & $29.20(46.8)$ & 37.76 (40.9) & 15.53 (79.7) & $23.77(68.8)$ & $29.65(70.1)$ \\
\hline $\begin{array}{l}\mathrm{AUC}_{t}, \mathrm{ng} \cdot \mathrm{h} / \mathrm{mL} \\
\text { mean }(\mathrm{CV})\end{array}$ & $242.74(46.7)$ & $369.91(39.5)$ & $484.09(42.4)$ & $178.86(74.6)$ & $277.58(67.8)$ & $370.29(60.4)$ \\
\hline $\begin{array}{l}\mathrm{AUC}_{\infty}, \mathrm{ng} \cdot \mathrm{h} / \mathrm{mL} \\
\quad \text { mean }(\mathrm{CV})\end{array}$ & $271.14(41.5)$ & $391.85(36.3)$ & $509.43(40.0)$ & $226.64(51.9)$ & $314.77(58.0)$ & $421.73(48.3)$ \\
\hline $\begin{array}{l}T_{\max }, \mathrm{h} ; \text { median } \\
\quad \text { (range) }\end{array}$ & $3.50(1.25-8.02)$ & $4.00(1.75-10.00)$ & $4.00(2.50-10.00)$ & $4.00(1.50-8.00)$ & $4.00(1.50-6.00)$ & $4.00(2.00-12.00)$ \\
\hline$T_{1 / 2 \mathrm{z}}, \mathrm{h} ;$ mean $(\mathrm{SD})$ & $7.44(2.04)$ & $7.43(2.09)$ & $7.44(1.57)$ & $7.24(2.25)$ & $6.89(1.73)$ & $6.82(1.37)$ \\
\hline
\end{tabular}

$A U C_{\infty}$ area under the plasma concentration-time curve measured from the time of dosing and extrapolated to infinity, $A U C_{t}$ area under the plasma concentration-time curve measured from the time of dosing to the last measurable concentration, $C_{\max }$ maximum observed plasma concentration, CTC Co-Crystal of Tramadol-Celecoxib, $C V$ coefficient of variation (\%), SD standard deviation, $T_{\text {max }}$ time to reach maximum observed plasma concentration, $T_{1 / 2 Z}$ terminal phase half-life

Table 7 Comparative bioavailability of $O$-desmethyltramadol (M1) after CTC administration in Japanese versus Caucasian subjects

\begin{tabular}{|c|c|c|c|c|c|c|}
\hline \multirow[t]{2}{*}{ Parameter } & \multirow[t]{2}{*}{ CTC dose (mg) } & \multirow[t]{2}{*}{ Number of subjects } & \multicolumn{2}{|l|}{ Non-weight adjusted } & \multicolumn{2}{|l|}{ Weight adjusted } \\
\hline & & & $\begin{array}{l}\text { Ratio (Japanese cohort/ } \\
\text { Caucasian cohort; \%) }\end{array}$ & $90 \% \mathrm{CI}$ & $\begin{array}{l}\text { Ratio (Japanese cohort/ } \\
\text { Caucasian cohort; \%) }\end{array}$ & $90 \% \mathrm{CI}$ \\
\hline \multirow[t]{3}{*}{$C_{\max }$} & 100 & $n=30^{\mathrm{a}} ; n=29^{\mathrm{b}}$ & 128.73 & $98.47,168.29$ & 125.24 & $93.56,167.64$ \\
\hline & 150 & $n=30^{\mathrm{a}} ; n=29^{\mathrm{b}}$ & 123.19 & $96.72,156.90$ & 121.51 & $93.35,158.16$ \\
\hline & 200 & $n=29^{\mathrm{a}} ; n=28^{\mathrm{b}}$ & 127.46 & $100.09,162.30$ & 125.53 & $96.32,163.59$ \\
\hline \multirow[t]{3}{*}{$\mathrm{AUC}_{t}$} & 100 & $n=30^{\mathrm{a}} ; n=29^{\mathrm{b}}$ & 136.30 & $106.09,175.11$ & 131.10 & $99.87,172.10$ \\
\hline & 150 & $n=30^{\mathrm{a}} ; n=29^{\mathrm{b}}$ & 133.83 & $107.05,167.32$ & 129.85 & $101.87,165.52$ \\
\hline & 200 & $n=29^{\mathrm{a}} ; n=28^{\mathrm{b}}$ & 130.59 & $104.58,163.07$ & 126.09 & $98.93,160.70$ \\
\hline \multirow[t]{3}{*}{$\mathrm{AUC}_{\infty}$} & 100 & $n=29^{\mathrm{a}} ; n=27^{\mathrm{b}}$ & 118.48 & $97.12,144.55$ & 115.43 & $93.17,143.01$ \\
\hline & 150 & $n=29^{\mathrm{a}} ; n=27^{\mathrm{b}}$ & 126.08 & $102.91,154.48$ & 121.31 & $97.43,151.04$ \\
\hline & 200 & $n=27^{\mathrm{a}} ; n=26^{\mathrm{b}}$ & 119.47 & $97.55,146.31$ & 111.35 & $89.57,138.42$ \\
\hline
\end{tabular}

$A U C_{\infty}$ area under the plasma concentration-time curve measured from the time of dosing and extrapolated to infinity, $A U C_{t}$ area under the plasma concentration-time curve measured from the time of dosing to the last measurable concentration, $C_{\text {max }}$ maximum observed plasma concentration, CTC Co-Crystal of Tramadol-Celecoxib, CI confidence interval

${ }^{\mathrm{a}}$ Japanese cohort

${ }^{\mathrm{b}}$ Caucasian cohort

This open-label study was randomised in nature and used cohorts that were well matched with respect to sex and BMI and of an adequate size to address the research question under investigation. The data reported here add to those obtained from earlier key phase 1 studies of CTC, conducted primarily in white or Caucasian subjects [10, 11]. In an earlier single-dose (200 mg CTC) phase 1 study, $T_{\max }$ values were slightly prolonged in the case of tramadol and were faster in the case of celecoxib, compared with those obtained after administration of reference products alone or in free combination. $C_{\max }$ values for tramadol and celecoxib were lower than after administration of reference products alone, as were AUC values for celecoxib (those for tramadol were similar to reference products alone) [11]. In a multiple-dose study, tramadol $C_{\max }$ and AUC were lower and $T_{\max }$ delayed after administration of CTC compared with the individual reference product alone or in free combination with celecoxib. In the case of celecoxib, $C_{\max }$ and AUC values were lower after CTC administration than after administration of celecoxib alone. Celecoxib's $C_{\max }$ was higher and $T_{\max }$ faster than for celecoxib administered in free combination with tramadol [10]. These pharmacokinetic profiles are broadly in line with those seen in the present study. The most common AEs in the present study were consistent with those reported for standard-formulation tramadol and celecoxib $[18,19]$, and with those reported in earlier trials of CTC [9-11].

Tramadol is largely metabolised by the isoenzyme CYP2D6. Levels of CYP2D6 activity are known to affect the pharmacokinetics of both tramadol and M1, including 
Fig. 4 Mean plasma concentration-time curves for celecoxib in Japanese (a) and Caucasian (b) cohorts. CTC Co-Crystal of Tramadol-Celecoxib
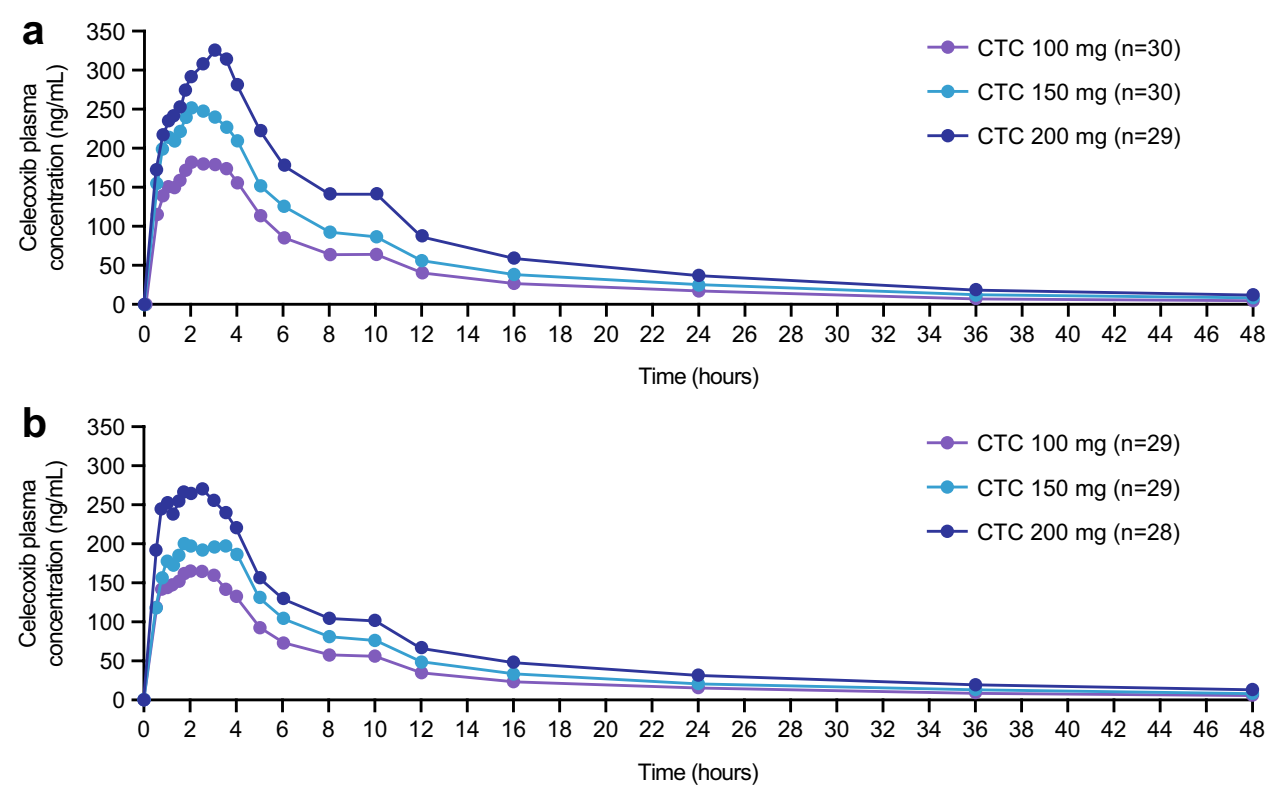

Table 8 Summary of celecoxib pharmacokinetic parameters after CTC administration in Japanese and Caucasian subjects

\begin{tabular}{|c|c|c|c|c|c|c|}
\hline \multirow[t]{2}{*}{ Parameter } & \multicolumn{3}{|l|}{ Japanese cohort } & \multicolumn{3}{|l|}{ Caucasian cohort } \\
\hline & $100 \mathrm{mg} \mathrm{CTC}(n=30)$ & $150 \mathrm{mg} \mathrm{CTC}(n=30)$ & $200 \mathrm{mg} \mathrm{CTC}(n=29)$ & $100 \mathrm{mg} \mathrm{CTC}(n=29)$ & $150 \mathrm{mg} \mathrm{CTC}(n=29)$ & $200 \mathrm{mg} \mathrm{CTC}(n=28)$ \\
\hline $\begin{array}{r}C_{\text {max }}, \mathrm{ng} / \mathrm{mL} ; \\
\text { mean }(\mathrm{CV})\end{array}$ & $230.7(31.7)$ & $305.4(29.1)$ & $380.4(28.1)$ & $199.0(39.8)$ & $251.0(32.5)$ & 330.4 (29.9) \\
\hline $\begin{array}{l}\mathrm{AUC}_{t}, \mathrm{ng} \cdot \mathrm{h} / \mathrm{mL} ; \\
\quad \text { mean }(\mathrm{CV})\end{array}$ & $1664.18(24.3)$ & $2424.91(21.5)$ & $3357.36(26.3)$ & $1521.79(28.3)$ & $2116.54(22.6)$ & $2821.11(23.4)$ \\
\hline $\begin{array}{l}\mathrm{AUC}_{\infty}, \mathrm{ng} \cdot \mathrm{h} / \mathrm{mL} ; \\
\quad \text { mean }(\mathrm{CV})\end{array}$ & $1821.03(23.3)$ & $2646.17(21.7)$ & $3671.80(28.6)$ & $1700.05(30.5)$ & $2404.01(20.5)$ & 3299.95 (23.6) \\
\hline $\begin{array}{l}T_{\max }, \mathrm{h} ; \text { median } \\
\quad \text { (range) }\end{array}$ & $2.00(0.50-5.00)$ & $2.00(0.75-6.00)$ & $3.00(0.50-6.00)$ & $2.00(0.50-4.00)$ & $2.50(0.75-4.00)$ & $1.75(0.50-4.00)$ \\
\hline$T_{1 / 2 \mathrm{Z}}, \mathrm{h} ;$ mean $(\mathrm{SD})$ & $12.95(5.56)$ & $16.83(9.41)$ & $14.81(7.01)$ & $16.91(6.21)$ & $18.85(7.36)$ & $18.66(8.74)$ \\
\hline
\end{tabular}

$A U C_{\infty}$ area under the plasma concentration-time curve measured from the time of dosing and extrapolated to infinity, $A U C_{t}$ area under the plasma concentration-time curve measured from the time of dosing to the last measurable concentration, $C_{\max }$ maximum observed plasma concentration, $C T C$ Co-Crystal of Tramadol-Celecoxib, $C V$ coefficient of variation (\%), $S D$ standard deviation, $T_{\max }$ time to reach maximum observed plasma concentration, $T_{1 / 2 Z}$ terminal phase half-life

in patients with pain [18, 20-22], and some studies report similar findings for CYP3A4 [18, 20-22]. CYP2D6 is subject to genetic polymorphisms that can have clinically relevant effects on analgesia [23], and tramadol pharmacogenomics is an area of growing importance in determining clinical treatment regimens [24]. Polymorphisms affecting tramadol pharmacokinetics, in particular CYP2D6*10, have been reported in some Asian populations [13, 14, 25, 26], including in Japanese subjects [15]. Differences in CYP3A4 expression levels between Japanese and Caucasian cohorts have also been reported [27]. CYP2D6*10 is associated with a low conversion of tramadol to M1 and is thought to have a high incidence in Japanese populations, occurring in approximately $20-45 \%$ of individuals [28]. In the present study, one subject (in the Caucasian cohort) appeared to have low $\mathrm{M} 1 /$ tramadol ratios and was therefore considered to possibly be a poor CYP2D6 metaboliser (although genotyping did not form part of the study). The influence of genetic polymorphisms on the metabolism of celecoxib is less clear. Celecoxib is primarily metabolised by CYP2C9 [19, 29], and while polymorphisms such as CYP2C9*3 have been reported to affect pharmacokinetics, including in Asian populations [16, 17], the clinical relevance of these findings is still subject to debate [29-31]. In the current study, some differences were seen in the pharmacokinetic exposure of tramadol and M1, although these were primarily accounted for by differences in body weight in the case of tramadol. Therefore, although genotyping was not conducted, these data suggest that CYP2D6 polymorphism status did not have a substantial impact 
Table 9 Comparative bioavailability of celecoxib after CTC administration in Japanese versus Caucasian subjects

\begin{tabular}{|c|c|c|c|c|c|c|}
\hline \multirow[t]{2}{*}{ Parameter } & \multirow[t]{2}{*}{ CTC dose (mg) } & \multirow[t]{2}{*}{ Number of subjects } & \multicolumn{2}{|l|}{ Non-weight adjusted } & \multicolumn{2}{|l|}{ Weight adjusted } \\
\hline & & & $\begin{array}{l}\text { Ratio (Japanese cohort/ } \\
\text { Caucasian cohort; \%) }\end{array}$ & $90 \% \mathrm{CI}$ & $\begin{array}{l}\text { Ratio (Japanese cohort/ } \\
\text { Caucasian cohort; \%) }\end{array}$ & $90 \% \mathrm{CI}$ \\
\hline \multirow[t]{3}{*}{$C_{\max }$} & 100 & $n=30^{\mathrm{a}} ; n=29^{\mathrm{b}}$ & 115.71 & $99.53,134.52$ & 113.27 & $96.17,133.41$ \\
\hline & 150 & $n=30^{\mathrm{a}} ; n=29^{\mathrm{b}}$ & 121.91 & $107.49,138.26$ & 123.90 & $108.05,142.07$ \\
\hline & 200 & $n=29^{\mathrm{a}} ; n=28^{\mathrm{b}}$ & 115.87 & $102.46,131.04$ & 121.41 & $106.42,138.51$ \\
\hline \multirow[t]{3}{*}{$\mathrm{AUC}_{t}$} & 100 & $n=30^{\mathrm{a}} ; n=29^{\mathrm{b}}$ & 109.50 & $97.90,122.48$ & 107.61 & $95.29,121.53$ \\
\hline & 150 & $n=30^{\mathrm{a}} ; n=29^{\mathrm{b}}$ & 114.78 & $104.56,126.01$ & 113.11 & $102.22,125.17$ \\
\hline & 200 & $n=29^{\mathrm{a}} ; n=28^{\mathrm{b}}$ & 119.85 & $108.41,132.49$ & 116.51 & $104.52,129.87$ \\
\hline \multirow[t]{3}{*}{$\mathrm{AUC}_{\infty}$} & 100 & $n=29^{\mathrm{a}} ; n=27^{\mathrm{b}}$ & 107.36 & $95.30,120.95$ & 104.70 & $92.26,118.82$ \\
\hline & 150 & $n=28^{\mathrm{a}} ; n=25^{\mathrm{b}}$ & 109.78 & $99.61,120.99$ & 106.93 & $96.33,118.69$ \\
\hline & 200 & $n=28^{\mathrm{a}} ; n=24^{\mathrm{b}}$ & 112.72 & $100.74,126.13$ & 108.40 & $96.42,121.88$ \\
\hline
\end{tabular}

$A U C_{\infty}$ area under the plasma concentration-time curve measured from the time of dosing and extrapolated to infinity, $A U C_{t}$ area under the plasma concentration-time curve measured from the time of dosing to the last measurable concentration, $C_{\text {max }}$ maximum observed plasma concentration, CTC Co-Crystal of Tramadol-Celecoxib, CI confidence interval

a Japanese cohort

${ }^{\mathrm{b}}$ Caucasian cohort

Table 10 Summary of adverse events reported in $\geq 5 \%$ of subjects in any dose group

\begin{tabular}{|c|c|c|c|c|c|c|c|c|}
\hline \multirow[t]{2}{*}{ Parameter } & \multicolumn{4}{|c|}{ Japanese cohort } & \multicolumn{4}{|c|}{ Caucasian cohort } \\
\hline & $\begin{array}{l}100 \mathrm{mg} \\
\text { CTC } \\
(n=30)^{\mathrm{a}}\end{array}$ & $\begin{array}{l}150 \mathrm{mg} \\
\text { CTC } \\
(n=30)^{\mathrm{a}}\end{array}$ & $\begin{array}{l}200 \mathrm{mg} \\
\text { CTC } \\
(n=29)^{\mathrm{a}}\end{array}$ & Total $(n=30)^{\mathrm{b}}$ & $\begin{array}{l}100 \mathrm{mg} \\
\text { CTC } \\
(n=29)^{\mathrm{a}}\end{array}$ & $\begin{array}{l}150 \mathrm{mg} \\
\text { CTC } \\
(n=29)^{\mathrm{a}}\end{array}$ & $\begin{array}{l}200 \mathrm{mg} \\
\text { CTC } \\
(n=29)^{\mathrm{a}}\end{array}$ & Total $(n=30)^{\mathrm{b}}$ \\
\hline Subjects reporting $\geq 1 \mathrm{AE}$ & $3(10.0)$ & $5(16.7)$ & $5(17.2)$ & $10(33.3)$ & $8(27.6)$ & $5(17.2)$ & $14(48.3)$ & $17(56.7)$ \\
\hline Nausea & 0 & 0 & $2(6.9)$ & $2(6.7)$ & 0 & 0 & $5(17.2)$ & $5(16.7)$ \\
\hline Dizziness & $1(3.3)$ & $1(3.3)$ & $2(6.9)$ & $3(10.0)$ & $1(3.4)$ & 0 & $1(3.4)$ & $2(6.7)$ \\
\hline Fatigue & 0 & 0 & $2(6.9)$ & $2(6.7)$ & 0 & 0 & 0 & 0 \\
\hline Hyperhidrosis & 0 & 0 & 0 & 0 & 0 & 0 & $2(6.9)$ & $2(6.7)$ \\
\hline $\begin{array}{l}\text { Subjects reporting } \geq 1 \\
\text { treatment-related } \mathrm{AE}\end{array}$ & $1(3.3)$ & $3(10.0)$ & $3(10.3)$ & $5(16.7)$ & $3(10.3)$ & $2(6.9)$ & $9(31.0)$ & $10(33.3)$ \\
\hline
\end{tabular}

Data shown are $x(\%)$, where $x$ is the number of subjects with data available and $\%$ is based on the number of subjects in population $(n)$

$A E$ adverse event, $C T C$ Co-Crystal of Tramadol-Celecoxib

${ }^{a}$ Number per dose, per cohort

${ }^{\mathrm{b}}$ Total number of individuals per cohort (as this is a crossover study, the same individual may present AEs in more than one dosing period)

on the pharmacokinetic exposure of tramadol after CTC administration in this study. Slight increases in celecoxib exposure were seen in Japanese versus Caucasian cohorts.

\section{Conclusion}

In conclusion, differences in tramadol, M1 or celecoxib pharmacokinetics between Japanese and Caucasian subjects following CTC administration were not sufficient to suggest that dose adjustment is required in Japanese subjects. In addition, exposure to each API within CTC increased with CTC dose in both populations and CTC was well tolerated in both cohorts. Following demonstration of efficacy in a phase 2 study of acute pain following an oral surgical procedure [9], CTC is now under evaluation in phase 3 studies of bunionectomy with osteotomy [32], acute pain following an oral surgical procedure [33] and hysterectomy-related pain [34].

Acknowledgements We thank all study participants and staff. The study was funded by Mundipharma Research Ltd (Cambridge, UK) 
and was carried out by Richmond Pharmacology Ltd (London, UK). Bioanalytical analyses were conducted by Laboratorios del Doctor Esteve, S.A.U. (ESTEVE). Pharmacokinetic analyses were conducted by Mundipharma Research Ltd. Medical writing support was provided by Hannah Mace MPharmacol, CMPP at Aspire Scientific (Bollington, UK), and was funded by Mundipharma Research GmbH \& Co. KG (Limburg, Germany). CTC is in development by Mundipharma Research and ESTEVE, as MR308 and E-58425.

\section{Compliance with Ethical Standards}

Funding This study was funded by Mundipharma Research Ltd (Cambridge, UK).

Conflict of interest UL is an employee of Richmond Pharmacology Ltd. MEn, MEs and GE are employees of Esteve. HD, GM, CB and KS are employees of Mundipharma Research Ltd. SM was an employee of Mundipharma Research $\mathrm{GmbH} \& \mathrm{Co} . \mathrm{KG}$ at the time the study was conducted. Esteve and Mundipharma are in collaboration for the development and commercialisation of CTC.

Ethical approval All procedures performed in studies involving human participants were in accordance with the ethical standards of the institutional and/or national research committee (South Central-Berkshire B Research Ethics Committee, UK; IRAS:188440; REC reference: 15/ SC/0549) and with the 1964 Helsinki Declaration and its later amendments or comparable ethical standards.

Informed consent Informed consent was obtained from all individual participants included in the study.

Open Access This article is distributed under the terms of the Creative Commons Attribution-NonCommercial 4.0 International License (http://creativecommons.org/licenses/by-nc/4.0/), which permits any noncommercial use, distribution, and reproduction in any medium, provided you give appropriate credit to the original author(s) and the source, provide a link to the Creative Commons license, and indicate if changes were made.

\section{References}

1. Shan N, Perry ML, Weyna DR, Zaworotko MJ. Impact of pharmaceutical cocrystals: the effects on drug pharmacokinetics. Expert Opin Drug Metab Toxicol. 2014;10(9):1255-71. https:// doi.org/10.1517/17425255.2014.942281.

2. Sekhon BS. Drug-drug co-crystals. Daru. 2012;20(1):45. https:// doi.org/10.1186/2008-2231-20-45.

3. Duggirala NK, Perry ML, Almarsson O, Zaworotko MJ. Pharmaceutical cocrystals: along the path to improved medicines. Chem Commun (Camb). 2016;52(4):640-55. https://doi.org/10.1039/ c5cc08216a.

4. Chou R, Gordon DB, de Leon-Casasola OA, Rosenberg JM, Bickler S, Brennan T, et al. Management of postoperative pain: a Clinical practice guideline from the American Pain Society, the American Society of Regional Anesthesia and Pain Medicine, and the American Society of Anesthesiologists' Committee on Regional Anesthesia, Executive Committee, and Administrative Council. J Pain. 2016;17(2):131-57. https://doi.org/10.1016/j. jpain.2015.12.008.
5. Yaksh TL, Woller SA, Ramachandran R, Sorkin LS. The search for novel analgesics: targets and mechanisms. F1000Prime Rep. 2015;7:56. https://doi.org/10.12703/p7-56.

6. Moore RA, Derry S, Aldington D, Wiffen PJ. Single dose oral analgesics for acute postoperative pain in adults-an overview of Cochrane reviews. Cochrane Database Syst Rev. 2015;9:CD008659. https://doi.org/10.1002/14651858.cd008 659.pub3.

7. Almansa C, Mercè R, Tesson N, Farran J, Tomàs J, Plata-Salamán CR. Co-Crystal of Tramadol hydrochloride-Celecoxib (CTC): a novel API-API co-crystal for the treatment of pain. Cryst Growth Des. 2017;17(4):1884-92. https://doi. org/10.1021/acs.cgd.6b01848.

8. Merlos M, Portillo-Salido E, Brenchat A. Administration of tramadol and celecoxib in a 1:1 molecular ratio produces synergistic antinociceptive effects in postoperative pain models: Preclinical rationale for clinical development of Co-Crystal of TramadolCelecoxib. IASP 2016; Yokohama: Abstract 2312 Poster Number PW.290.

9. López-Cedrún J, Videla S, Burgueño M, Juárez I, Aboul-Hosn S, Martín-Granizo R, et al. Co-Crystal of Tramadol-Celecoxib in patients with moderate to severe acute post-surgical oral pain: a dose-finding, randomised, double-blind, placebo- and active-controlled, multicentre, phase II trial. Drugs R D. 2018;18(2):137-48. https://doi.org/10.1007/s40268-018-0235-y.

10. Videla S, Lahjou M, Vaque A, Sust M, Escriche M, Soler L, et al. Pharmacokinetics of multiple doses of Co-Crystal of TramadolCelecoxib: findings from a 4-way randomized open-label phase I clinical trial. Br J Clin Pharmacol. 2018;84(1):64-78. https://doi. org/10.1111/bcp.13428.

11. Videla S, Lahjou M, Vaque A, Sust M, Encabo M, Soler L, et al. Single-dose pharmacokinetics of Co-Crystal of Tramadol-Celecoxib: results of a four-way randomized open-label phase I clinical trial in healthy subjects. Br J Clin Pharmacol. 2017;83(12):2718-28. https://doi.org/10.1111/bcp.13395.

12. Wang B, Wang J, Huang SQ, Su HH, Zhou SF. Genetic polymorphism of the human cytochrome P450 2C9 gene and its clinical significance. Curr Drug Metab. 2009;10(7):781-834.

13. Leppert W. CYP2D6 in the metabolism of opioids for mild to moderate pain. Pharmacology. 2011;87(5-6):274-85. https://doi. org/10.1159/000326085.

14. Gan SH, Ismail R, Wan Adnan WA, Zulmi W. Impact of CYP2D6 genetic polymorphism on tramadol pharmacokinetics and pharmacodynamics. Mol Diagn Ther. 2007;11(3):171-81.

15. Kubota T, Yamaura Y, Ohkawa N, Hara H, Chiba K. Frequencies of CYP2D6 mutant alleles in a normal Japanese population and metabolic activity of dextromethorphan $O$-demethylation in different CYP2D6 genotypes. Br J Clin Pharmacol. 2000;50(1):31-4.

16. Kim SH, Kim DH, Byeon JY, Kim YH, Kim DH, Lim HJ, et al. Effects of CYP2C9 genetic polymorphisms on the pharmacokinetics of celecoxib and its carboxylic acid metabolite. Arch Pharm Res. 2017;40(3):382-90. https://doi.org/10.1007/s1227 2-016-0861-2.

17. Liu R, Gong C, Tao L, Yang W, Zheng X, Ma P, et al. Influence of genetic polymorphisms on the pharmacokinetics of celecoxib and its two main metabolites in healthy Chinese subjects. Eur J Pharm Sci. 2015;79:13-9. https://doi.org/10.1016/j.ejps.2015.09.005.

18. European Medicines Agency. Summary of product characteristics for tramadol hydrochloride $50 \mathrm{mg}$ capsules. 2017. http://www. medicines.org.uk/EMC/medicine/24186/SPC. Accessed 23 Oct 2017.

19. European Medicines Agency. Summary of product characteristics for Celebrex $100 \mathrm{mg}$ capsule. 2016. http://www.medicines.org.uk/ emc/medicine/14534. Accessed 25 Oct 2017. 
20. Saarikoski T, Saari TI, Hagelberg NM, Backman JT, Neuvonen PJ, Scheinin M, et al. Effects of terbinafine and itraconazole on the pharmacokinetics of orally administered tramadol. Eur J Clin Pharmacol. 2015;71(3):321-7. https://doi.org/10.1007/s0022 8-014-1799-2.

21. Stamer UM, Musshoff F, Kobilay M, Madea B, Hoeft A, Stuber F. Concentrations of tramadol and $O$-desmethyltramadol enantiomers in different CYP2D6 genotypes. Clin Pharmacol Ther. 2007;82(1):41-7. https://doi.org/10.1038/sj.clpt.6100152.

22. de Moraes NV, Lauretti GR, Coelho EB, Godoy AL, Neves DV, Lanchote VL. Impact of fraction unbound, CYP3A, and CYP2D6 in vivo activities, and other potential covariates to the clearance of tramadol enantiomers in patients with neuropathic pain. Fundam Clin Pharmacol. 2016;30(2):153-61. https://doi.org/10.1111/ fcp. 12168 .

23. Lassen D, Damkier P, Brosen K. The pharmacogenetics of tramadol. Clin Pharmacokinet. 2015;54(8):825-36. https://doi. org/10.1007/s40262-015-0268-0.

24. Miotto K, Cho AK, Khalil MA, Blanco K, Sasaki JD, Rawson $\mathrm{R}$. Trends in tramadol: pharmacology, metabolism, and misuse. Anesth Anal. 2017;124(1):44-51. https://doi.org/10.1213/ ane.0000000000001683.

25. Xu J, Zhang XC, Lv XQ, Xu YY, Wang GX, Jiang B, et al. Effect of the cytochrome P450 2D6*10 genotype on the pharmacokinetics of tramadol in post-operative patients. Pharmazie. 2014;69(2):138-41.

26. Li Q, Wang R, Guo Y, Wen S, Xu L, Wang S. Relationship of CYP2D6 genetic polymorphisms and the pharmacokinetics of tramadol in Chinese volunteers. J Clin Pharm Ther. 2010;35(2):239-47. https://doi.org/10.111 1/j.1365-2710.2009.01102.x.

27. Yamaori S, Yamazaki H, Iwano S, Kiyotani K, Matsumura K, Saito T, et al. Ethnic differences between Japanese and Caucasians in the expression levels of mRNAs for CYP3A4, CYP3A5 and CYP3A7: lack of co-regulation of the expression of CYP3A in Japanese livers. Xenobiotica. 2005;35(1):69-83. https://doi. org/10.1080/00498250400021796.

28. Raffa RB. Tramadol in Japanese population: the relative contribution of M1 metabolite as assessed by CYP2D6*10 genotype. Pharmacol Pharm. 2012;3:337-41. https://doi.org/10.4236/ pp.2012.33045.

29. Gong L, Thorn CF, Bertagnolli MM, Grosser T, Altman RB, Klein TE. Celecoxib pathways: pharmacokinetics and pharmacodynamics. Pharmacogenet Genom. 2012;22(4):310-8. https:// doi.org/10.1097/FPC.0b013e32834f94cb.

30. Kirchheiner J, Stormer E, Meisel C, Steinbach N, Roots I, Brockmoller J. Influence of CYP2C9 genetic polymorphisms on pharmacokinetics of celecoxib and its metabolites. Pharmacogenetics. 2003;13(8):473-80.

31. Prieto-Perez R, Ochoa D, Cabaleiro T, Roman M, Sanchez-Rojas $\mathrm{SD}$, Talegon M, et al. Evaluation of the relationship between polymorphisms in CYP2C8 and CYP2C9 and the pharmacokinetics of celecoxib. J Clin Pharmacol. 2013;53(12):1261-7. https://doi. org/10.1002/jcph.169.

32. ClinicalTrials.gov. Co-crystal E-58425 vs tramadol and celecoxib for moderate to severe acute pain after bunionectomy. Phase III clinical trial. 2017. https://clinicaltrials.gov/ct2/show/NCT03 108482. Accessed 18 Dec 2017.

33. ClinicalTrials.gov. Efficacy and safety in a randomised acute pain study of MR308 (Tramadol/Celecoxib). (STARDOM1). 2017. https://clinicaltrials.gov/ct2/show/NCT02982161?term=MR308 \&rank=1. Accessed 12 Oct 2017.

34. ClinicalTrials.gov. Efficacy and safety in a randomised acute pain study of MR308: STARDOM2. (STARDOM2). 2017. https://clini caltrials.gov/ct2/show/NCT03062644?term=MR308\&rank=2. Accessed 12 Oct 2017. 